\title{
Disparities in Sportspersons' Sleep Behaviour due to COVID-19 Pandemic Lockdown in India
}

Dr. W. Vinu

Assistant Professor, Department of Physical Education, Annamalai University, Tamilnadu, India.

DOI: http://doi.org/10.38177/ajast.2021.5218

Copyright: $\odot 2021$ W.Vinu. This is an open access article distributed under the terms of the Creative Commons Attribution License, which permits unrestricted use, distribution, and reproduction in any medium, provided the original author and source are credited.

\section{AB STR ACT}

Many types of research over several decades prove that sleep is a significant factor for human performance. The sleep behaviour of sportspersons in particular is very different from the normal folks or members of other occupational groups such as police and the military, office-going folks. Henceforth, this study is projected to investigate the changes in sports persons' sleep behaviour due to the COVID-19 lockdown in India. For which, the survey was conducted among 514 sportspersons representing various Universities ( 296 male/218 female) across various states of India using a simple random sampling technique. The composed data were analyzed using a paired samples t-test. The results of this study indicated that the sleep behaviour of sportspersons was affected during the COVID-19 lockdown in India.

Keywords: Sports persons' sleep behaviour, COVID-19 pandemic lockdown, India.

\section{Introduction}

Researches over several decades prove that sleep is one of the important factors for human performance in sports (Dijk et al., 1992; Van Dongen \& Dinges, 2003; Cohen et al., 2010). The duration of the wake period, as well as the biological time of day, decided the structure of sleep and the amount of sleepiness (Vila \& Samuels, 2010). Duration of sleep, quality, and the circadian rhythm are considered important factors in terms of the overall convalescent result of sleep (Belenky et al., 2003). Furthermore, the waste products of neuronal activity accumulate during sleeplessness is processed and clearance of toxic waste and impedes regular neuronal performance. Various researches about sleep have been done in different areas such as law enforcement (Vila, 2000; Vila et al., 2005; Vila, 2006; Vila \& Samuels, 2010), the military (Haslam, 1982; Miller \& Nguyen, 2003; Doheney, 2004; Arendt et al., 2006) or aviation (Neri \& Shappell, 1992; Brown, 2000; Dijk et al., 2001; Caldwell, 2005). But, the sportspersons in specific are very compared to the average individual or members of occupational groups such as law enforcement and the military, on whom prior research is based.

Because, the physical and mental demands of sportspersons are unique, (Arun Mozhi and Vinu 2019) aggressive in nature aggressive behavior is the intention underlying the actor's behavior. In this connection, Halson (2008) and Leeder et al. (2012) observed sleep because of the excellent psycho-physiological method to be had for the recuperation of elite sports activities people. Thus, quantifying and measuring sleep among sports activities people in the game placing has to grow to be not unusual place prevalence (Caia et al., 2017). Preliminary findings concerning traditional sleep periods of sports activities people indicated that seven hours of sleep in step with night time in normal conditions as every day (Lastella et al., 2015 and Leeder et al., 2012). Sports people's loss of sleep resulted from many severe consequences. Similarly, a couple of nights time of decreased sleep ended in bad effects. Following a nightly ration of $3 \mathrm{~h}$ of sleep for 3 successive nights, the overall performance of sports activities people's obligations considerably reduced on the second one day and the said deteriorations had been pronounced 
in sports activities people' temper states (Reilly \& Piercy, 1994). Axelsson et.al. (2008) investigated the accumulation of sleepiness during five consecutive restricted nights with $4 \mathrm{hrs}$ of sleeping and found that median reaction times and sleepiness returned to baseline during seven recovery days, while lapses were still increased. Belenky et.al. (2003) made another sleep-dose-response study and found that seven days with 5hours and 7hours of sleep restriction initially resulted in a declined performance in the psychomotor vigilance task which appeared to stabilize at a lower-than-baseline level after a few days aggression level increased.

In that same study, it's far observed that 3hours of excessive sleep limit declined overall performance constantly and 3 days of 8 hours recuperation sleep did now no longer repair overall performance to baseline levels. Consequently, cumulative sleep loss reasons an oxidant imbalance (Miller \& (Miller \& Nguyen, 2003). However, these findings should be treated with caution because of differences in study design used in various studies and small sample sizes, these findings underline the importance of sufficient sleep. There are several reasons which affect the sleep behaviour of sportspersons. As a matter of course, sleep/wake patterns do not emerge identically every night. Therefore, it is foremost important to investigate the changes in sports persons' sleep in different contexts. In this context, this study is proposed to examine whether there exists any difference in the average intensity of sports persons' sleep behaviour before and during the COVID-19 lockdown in India.

\section{Methods}

\subsection{Participants}

This survey was completed by a sample of 514 participants of (296 male/218 female) across selected universities in India. All participants for both groups were aged between 18-28 yrs at the time of taking part in the study. The individuals on special occasions like marriage in the family, death in the family, the birth of a child, and any function were excluded from taking part in the study. The 'athlete' population used in the current study included sportspersons representing selected universities in different events. Irrespective of the event, the complete list of sportspersons in selected universities was prepared and from that list, 514 participants were selected using a simple random sampling technique.

The data were collected from the samples using well-structured questionnaires. The questionnaires were administered to all participants via email and google forms. All questionnaires asked participants to answer the questions relating to their normal sleep behaviour (i.e before lockdown) and sleep behaviour during the COVID-19 lockdown period. The data were collected during the period of the second lockdown in India (i.e. May-2021 to June 2021).

\subsection{Measure}

In the questionnaire, the data concerning sports persons' sleep behaviours data was collected using the sports persons' sleep behaviour Questionnaire (ASBQ) by Driller et al., (2018). Rather than a clinical screening tool, the ASBQ is an 18-item survey to identify areas of sleep behaviour.

The 18- items measuring three challenges of sleep behaviour namely Routine/environmental factors (6 items), Behavioural factors ( 7 items), and Sport-related factors (5 items). The survey asks participants how frequently they 
engage in specific behaviours (never, rarely, sometimes, frequently, and always). Scoring for each response $(1=$ never, $2=$ rarely, $3=$ sometimes, $4=$ frequently, $5=$ always) were summed independently to obtain the mean scores of each component independently. But in all cases, higher scores indicate poor sleep behaviours.

\subsection{Statistical tool used}

The collected data were analyzed using a paired sample t-test, which is a type of inferential statistic used to determine whether there exists a significant difference between the means of two tests on the same persons before and during COVID-19 lockdown. The t-test tells you how significant the differences between tests are; In other words, it lets you know if those differences (measured in means/averages) could have happened by chance. A t-test is used as a hypothesis testing tool, which allows testing of an assumption applicable to a population.

\section{Analysis and Interpretation}

In order to examine whether there exists a significant difference between the average intensity of sports persons' sleep behaviour before COVID-19 lockdown and the average intensity of sports persons' sleep behaviour during COVID-19 lockdown.

The totality of each component of sports persons' sleep behaviour before COVID-19 lockdown which represents the intensity of each challenge faced by sports persons was taken individually. Similarly, the totality of each component of sports persons' sleep behaviour during COVID-19 lockdown which represents the intensity of each challenge faced by sports persons was taken individually. The below stated null hypothesis was formulated, to test the formulated hypothesis paired sample t-test was computed and the results were presented in the following consolidated table.

H0: Average intensity of sports persons' sleep behaviour before and during COVID-19 lockdown remains same.

Table 1. Paired Samples Statistics

\begin{tabular}{|ll|r|r|r|r|r|}
\hline & & Mean & N & \multicolumn{1}{c|}{$\begin{array}{c}\text { Std. } \\
\text { Deviation }\end{array}$} & t value & p (sig) \\
\hline Routine/environmental factors & $\begin{array}{l}\text { Before } \\
\text { COVID-19 }\end{array}$ & 14.1304 & 514 & 3.54318 & -56.752 & .000 \\
& After COVID- 19 & 24.0136 & 514 & 2.58309 & & \\
\hline Behavioral factors & $\begin{array}{l}\text { Before } \\
\text { COVID-19 }\end{array}$ & 14.0311 & 514 & 3.41522 & -63.646 & .000 \\
& After COVID- 19 & 26.9436 & 514 & 3.60889 & & .000 \\
\hline Sport-related factors & Before & 13.2763 & 514 & 3.51182 & -38.563 & \\
\hline
\end{tabular}




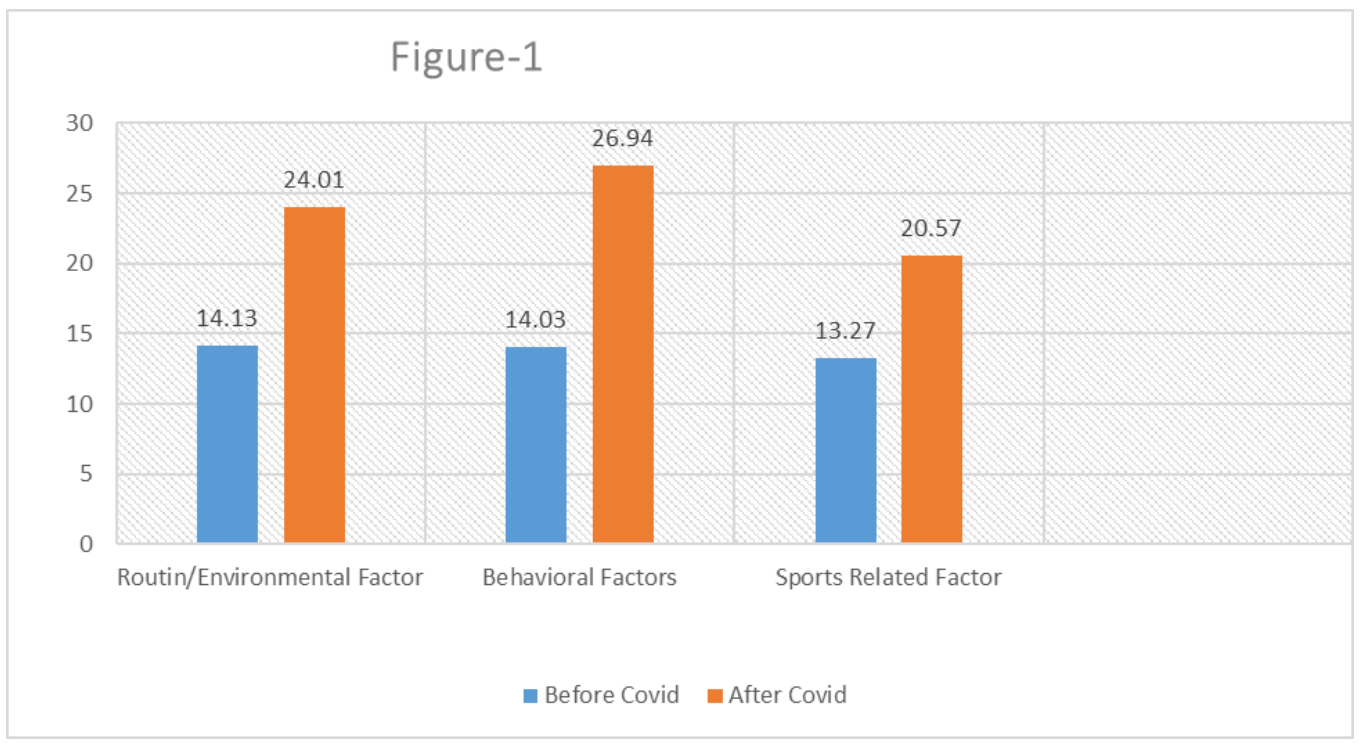

In the above table, the p-value for routine/environmental factors, behavioural factors, and sport-related factors was found to be 0.000 . Since all the values of $p<0.005$, the null hypothesis was rejected. Hence, it was found that the average intensity of challenges faced by sports persons before and during COVID-19 lockdown differs significantly in all three cases. The $\mathrm{t}$ values were found to be $-56.75,-63.646$, and -38.563 for routine/ environmental factors, behavioural factors, and sport-related factors respectively.

These larger t-values pronounced more difference between the before and during COVID-19 lockdown period sports persons' sleep behaviour and also indicated that the probability of difference occurred by chance was smaller. The mean difference of $-9.88327,-12.91245$, and -7.29961 clearly represented that the average scores of during COVID-19 were higher than the average scores of before COVID-19 in all the three cases.

This clearly specified that the challenges faced by the sportspersons during COVID-19 were higher than the challenges faced by the sportspersons before COVID-19. Finally, all the values in the table confirmed that COVID-19 lockdown made the many sportspersons poorer sleepers.

\section{Conclusions}

Sleep is an important factor for human performance. Various researches about sleep have been done in different areas such as law enforcement (4-7), the military (8-11), or aviation (12-15). But, researches about the sleep of the sportspersons, in particular, are limited. There are several reasons which affect the sleep behaviour of sportspersons.

Therefore, it is foremost important to investigate the changes in sports persons' sleep in different contexts. In this context, this study is proposed to examine whether there exists any difference in the average intensity of sports persons' sleep behaviour before and during the COVID-19 lockdown in India.

For which, the survey was conducted among 514 sportspersons representing various Universities (296 male/218 female) across various states of India using the snowball sampling technique. The collected data were analyzed using a paired samples t-test. The results of this study indicated that the sleep behaviour of sportspersons was affected during the COVID-19 lockdown in India. 


\section{Declarations}

\section{Source of Funding}

This research did not receive any grant from funding agencies in the public, commercial, or not-for-profit sectors.

\section{Competing Interests Statement}

The author declares no competing financial, professional and personal interests.

\section{Ethical Approval}

Ethical approval for this research was given based on institutional guidelines.

\section{Consent for publication}

Author declares that he/she consented for the publication of this research work.

\section{Availability of data and material}

Author is willing to share data and material according to the relevant needs.

\section{References}

1. Dijk DJ, Duffy JF, Czeisler CA. Circadian and sleep/wake dependent aspects of subjective alertness and cognitive performance. J Sleep Res 1992; 1:112-117.

2. Van Dongen HPA, Dinges DF. Investigating the interaction between the homeostatic and circadian processes of sleep-wake regulation for the prediction of waking neurobehavioural performance. J Sleep Res 2003; 12:181-187.

3. Cohen DA, Wang W, Wyatt JK, Kronauer RE, Dijk D, Czeisler CA et al. Uncovering residual effects of chronic sleep loss on human performance. Sci Transl Med 2010; 2:14.

4. Vila BJ. Tired cops: the importance of managing police fatigue. Washington DC: Police Executive Research Forum 2000.

5. Vila BJ, Morrison GB, Kenney DJ. Improving shift schedule and workhour policies and practices to increase police officer performance, health, and safety. Police quarterly 200; 5: 4-24.

6. Vila BJ. Impact of long work hours on police officers and the communities they serve. Am J Ind Med 2006; 49:972-980.

7. Vila B, C Samuels. Sleep problems in first responders and the military. In: Kryger MH, Roth T, Dement WC eds. Principles and Practice of Sleep Medicine, 5th ed. Philadelphia, Pennsylvaia: Elsevier Saunders 2010.

8. Haslam, DR. Sleep loss, recovery sleep and military performance. Ergonomics 1982; 25:163-178.

9. Miller NL, Nguyen J. Working the nightshift on the USS STENNIS: implications for enhancing warfighter effectiveness. Proceedings of the Human Systems Integration Symposium 2003.

10. Doheney SW. Sleep logistics as a force multiplier: an analysis of reported fatigue factors from Southwest Asia warfighters. Thesis 2004. Monterey, California: Naval Postgraduate School. 
11. Arendt J, Middleton B, Williams P, Francis G, Luke C. Sleep and circadian phase in a ship's crew. J Biol Rhythms 2006; 21: 214-221.

12. Neri DF, Shappell SA. Work/rest Schedules and Performance of S-3 Aviators during Fleet Exercise 1992 (NAMrL-1382). Pensacola, Florida: Naval Aerospace Medical Research Laboratory 1993.

13. Brown D. Performance Maintenance during Continuous Flight operations, A Guide for Flight Surgeons (No. NAVMED P-6410. (01 Jan 2000)).

14. Dijk DJ, DF Neri, JK Wyatt, JM Ronda, E Riel, A Ritz-De Cecco et al. Sleep, performance, circadian rhythms, and light-dark cycles during two space shuttle flights. Am J Physiol 2001; 281: R1647-1664.

15. Caldwell JA. Fatigue in aviation. Travel Med Infect Dis 2005; 3:85-96.

16. Halson SL. Nutrition, sleep and recovery. Eur J Sport Sci. 2008; 8(2):119- 26, DOI: http://dx.doi.org/10.1080/1 7461390801954794.

17. Leeder J, Glaister M, Pizzoferro K, Dawson J, Pedlar C. Sleep duration and quality in elite sports persons measured using wristwatch actigraphy. J Sports Sci. 2012; 30(6):541-5, DOI: http://dx.doi.org/10.1080/02640414. 2012.660188.

18. Caia J, Thornton HR, Kelly VG, Scott TJ, Halson SL, Cupples B, et al. Does self-perceived sleep reflect sleep estimated via activity monitors in professional rugby league sports persons? J Sports Sci. 2017:1-5. PMID: 29087784, DOI: http://dx.doi.org/10.1080/02640414.2017.1398885.

19. Lastella M, Roach GD, Halson SL, Sargent C. Sleep/wake behaviours of elite sports persons from individual and team sports. Eur J Sport Sci. 2015; 15: 94-100, DOI:10.1080/17461391.2014.932016.

20. Lee A, Galvez JC. Jet lag in sports persons. Sports Health. 2012; 4: 211-216, DOI:10.1177/1941738112442340.

21. Leeder J, Glaister M, Pizzoferro K, Dawson J, Pedlar C. Sleep duration and quality in elite sports persons measured using wristwatch actigraphy. J Sports Sci. 2012; 30: 541-545, DOI:10.1080 /02640414.2012.660188

22. Reilly T, Piercy M. The effect of partial sleep deprivation on weight-lifting performance. Ergonomics. 1994; 37: 107-115, DOI:10.1080/00140139408963628.

23. Axelsson J, Kecklund G, Åkerstedt T, Donofrio P, Lekander M, Ingre M. Sleepiness and performance in response to repeated sleep restriction and subsequent recovery during semilaboratory conditions. Chronobiol Int. 2008; 25: 297-308, DOI:10.1080/07420520802107031.

24. Belenky G, Wesensten NJ, Thorne DR, Thomas ML, Sing HC, Redmond DP, Russo MB, Balkin TJ. Patterns of performance degradation and restoration during sleep restriction and subsequent recovery: A sleep dose-response study. J Sleep Res. 2003; 12: 1-12, DOI:10.1046/j.1365-2869.2003.00337.x.

25. Arun Mozhi and W Vinu A comparative study of aggression between men and women kabaddi and kho-kho players International Journal of Physiology, Nutrition and Physical Education 2019; 4(1): 380-382. 